\section{APS and MRS release joint report on critical elements for energy}

\author{
www.mrs.org/advocacy/ece
}

T he American Physical Society (APS) and the Materials Research Society (MRS) released a report in February during the AAAS meeting that delineates a plan to secure future supplies of rare earths and other elements critical to the development of new technologies to foster U.S energy independence.

As described in Energy Critical Elements: Securing Materials for Emerging Technologies, energy-critical elements (ECEs) are chemical elements that have the capacity to transform the way we capture, transmit, store, or conserve energy. In addition to rare earth elements, ECEs potentially include more than a dozen others, such as indium, lithium, and tellurium-used in electric cars, wind turbines, and solar cells.

"Our report outlines a plan that can help the U.S. take control of its energy future," said Robert Jaffe, Morningstar Professor of Physics at the Massachusetts Institute of Technology and co-chair of the APS-MRS study group. "No country can mine its way to ECE independence. Instead, we need to develop an integrated approach to securing supplies of these key materials."

The report cautions against stockpiling the elements, pointing out that the method is a disincentive to innovation. Instead, it calls for stabilizing ECE supplies using a multifaceted approach that includes substitutional research, enhanced recycling and gathering, and disseminating accurate information about ECE availability. Using these approaches, General Electric successfully redesigned its high performance turbines while anticipating a shortage of rhenium, an ECE, according to the report.

Elements can be deemed "energycritical" for various reasons. Some are simply rare in the Earth's crust or poorly concentrated by geological processes. Others occur only in a few mines worldwide, or production might be dominated by, and therefore subject to, manipulation by one or more countries. The United States relies on other countries for more than $90 \%$ of most of the ECEs identified in the report. China produces $95 \%$ of all rare-earth elements and recently announced plans to cut its exports of the minerals to various nations by $35 \%$. Many ECEs have been produced as by-products of primary metals refining, complicating attempts to produce large quantities. Because they are relatively scarce, extraction of ECEs often involves processing large amounts of material, sometimes in ways that do unacceptable environmental damage.

To deal with the multifaceted issue of ECE availability, the APS-MRS report makes several recommendations. Regarding information on collection and analysis, the report says the U.S. government should gather, analyze, and disseminate information on energycritical elements across the lifecycle supply chain, including discovered and potential resources, production, use, trade, disposal, and recycling. The federal government should regularly survey emerging technologies and the supply chain for elements throughout the periodic table with the aim of identifying critical applications, as well as potential shortfalls. The entity undertaking this task should be a Principal Statistical Agency, a designation that would enable it to require compliance with requests for information. Comprehensive, reliable, and up-to-date information on all aspects of the lifecycle of ECEs would enable researchers, developers, and investors to plan more successfully for the materials needs of new technologies.

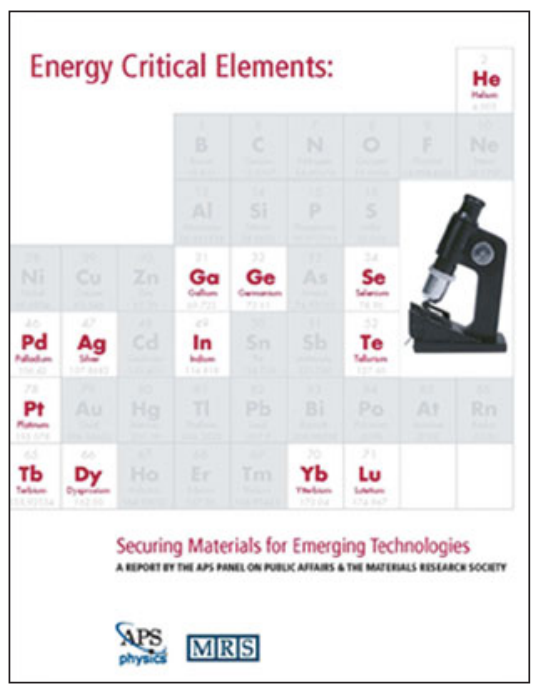

The report also recommends the federal government establish a research and development effort focused on energycritical elements and possible substitutes that can enhance vital aspects of the supply chain, including MRS geological deposit modeling, mineral extraction and processing, material characterization and substitution, utilization, manufacturing, recycling, and lifecycle analysis. Such an effort would also address critical, but manageable, workforce needs.

The federal government should establish a consumer-oriented "Critical Materials" designation for ECE-related products, said the report. At the same time, steps should be taken to improve rates of post-consumer collection of industrial and consumer products containing ECEs, beginning with an examination of the numerous methods being explored and implemented in various states and countries.

The study committee does not recommend that the federal government establish non-defense-related economic stockpiles of ECEs with the exception of one element: helium. It is unique among energy-critical elements because helium is permanently lost to the atmosphere if it is not captured during natural gas extraction. Measures should be adopted that will both conserve and enhance the country's helium reserves, said the committee.

The report can be accessed from the MRS website at www.mrs.org/advocacy/ ece. 